\title{
Innovative Poly Methyl Acrylate Intubation Device Used in Difficult Airway Instrumentation of Patients with Pharyngeal Tumors
}

\author{
RAZVAN HAINAROSIE ${ }^{1.2}$, NARCIS TANASE ${ }^{3}$, VIOREL ZAINEA ${ }^{1,2}$, CATALINA PIETROSANU1*, IRINA IONITA ${ }^{1}$, \\ DRAGOS CRISTIAN STEFANESCU 4 \\ ${ }^{1}$ Carol Davila University of Medicine and Pharmacy, $8^{\text {th }}$ Eroii Sanitari Blvd., 050474, Bucharest, Romania \\ 2 Prof. Dr. D. Hociota Institute of Phonoaudiology and Functional ENT Surgery, 21 $1^{\text {st }}$ Mihail Cioranu Str., 050751, Bucharest, \\ Romania \\ ${ }^{3}$ Central Military Hospital, $88^{\text {th }}$ Mircea Vulcanescu Str.,010825, Bucharest, Romania \\ ${ }^{3}$ Gen. Dr. Aviator Victor Anastasiu Institute of Aeronautical and Spatial Medicine, 88 Mircea Vulcanescu, 010825, Bucharest, \\ Romania
}

\begin{abstract}
Difficult airway management is a common situation when the anesthesiologist deals with patients with hypo pharyngeal tumors. The volume of the tumor usually covers the glottis plan and modifies the local anatomy, making the intubation process difficult or almost impossible. Intubation laryngoscopes developments are minor and adding a CCD camera at the tip of the laryngoscope is the best improvement made in our days. Today, on the market, an intubation device designed properly for the patients with extensive hypo pharyngeal tumors does not exist. The aim of the paper is to present an innovative device designed for patients with hypo pharyngeal tumors.
\end{abstract}

Keywords: difficult airway management, hypo pharyngeal tumors

Difficult airway management is one of the greatest challenges and responsibilities that the anesthesiologist will always face. No matter how well trained or experienced he/she is, cases in which airway instrumentation will prove problematic will always exist.

The most important aspect of the successful approach in such cases is the preliminary training for that situation $[1,2]$. Often, in crisis situations, when facing a problematic patient, it may be too late to ensure the availability of adequate equipment and it could prove difficult to set up a reserve plan or find alternative strategies.

The difficult airway (difficult intubation) is defined according to the American Society of Anesthesiologists (ASA) standards as the tracheal intubation that requires more than three attempts performed by an experienced anesthesiologist. In 1993, the firstASA guidelines on difficult airline management were published; since then, they have also benefited from an update in 2013, and by the end of 2015, the DifficultAirway Society (DAS) will publish guides for the approach of unplanned difficult airways in adults [3].

Difficult Airway Management is based on an algorithm (protocol) that includes different combinations or options that depend on the status of the patient at some point during the procedure. Equipment and devices (probes, masks, mandrels, etc.) are varied, but they all have the same ultimate goal: to ensure fast and safe airway approach. The new guides consist of a series of sequential (A-D) plans that can be used if tracheal intubation fails and focus on ensuring adequate oxygenation of the patient in these situations, limiting the number of attempts to track the pathway in order to reduce the incidence of complications.

Plan A - Key Elements:

1. Correct position of the patient

2. Pharmacological optimization; correct choice of induction drugs

3. Appropriate pre-oxygenation

4. Videolaringoscopy (novelty element) - provides better view of the glottis space;
5. MAXIMUM 3 attempts at laryngoscopy

If Plan A Fails -

Plan B - key elements:

1. Maintaining oxygenation

2. Declare difficult intubation and ask for help

3. Supraglottis devices (e.g., the standard laryngeal mask or the 2nd generation of masks type)

4. MAXIMUM 3 attempts to apply the supraglottis device If plan $B$ fails -

Plan C

1.Declared impossible ventilation via supraglottis device, flexible fibroscopic examination Bonfils (Karl Storz), use Proseal LMA or LMA Supreme [4]

2. Facial mask oxygenation: if possible, the patient is woken up

3. If ventilation and oxygenation are not possible with all the measures presented above, the patient should be cleansed and oxygenation efforts will continue and he will be declared CICV (can'tintubate, can't ventilate) and apply plan D

Plan D

1. A didactical access technique with a scissor blade or with blade no. 10, via the intercricothyroid membrane will be performed

2. A balloon intubation probe of the largest caliber will be placed through the incision

3. Ventilation is not recommended through the smalldiameter cannula inserted through the intercricothyroid incision

4. The technique should be known by any anesthesiologist and should be exercised periodically

\section{Experimental part}

Huge tumor mass arising from the hypo pharynx will majorly modify the anatomy of the region [5]. In most of the cases the glottis plan will be impossible to see because the tumor mass will cover it. This is especially problematic for problematic for pharyngolaryngeal tumors, where the local anatomy is significantly modified and the available

* email: catapietrosanu@gmail.com; Phone: 0723627405 


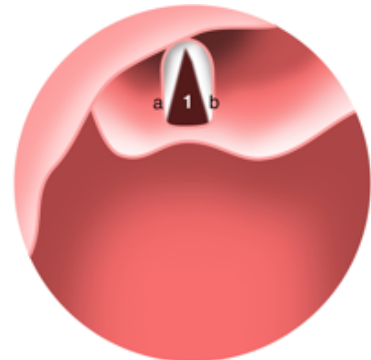

Fig. 1. Normal aspect of the glottis plan; a - left vocal cord; b- right vocal fold; 1 - glottis plan

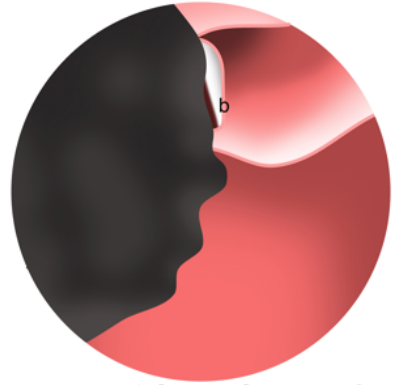

Fig. 2. Left hypo pharyngeal tumor covering the glottis plan - difficult intubation space is narrow $[6,7]$. Although in such cases, often inoperable, systemic and local delivered chemotherapy may associate positive results under the supervision of the oncologist [8], the challenge for these this patients is to obtain a biopsy. Current intubation laryngoscopes do not permit pushing away the tumor from the glottis plan in order to see and approach the airway (fig. 1 and fig. 2). Those type of tumors will usually bleed in when they are manipulated.

We designed a special instrument to approach the airway in cases of large tumors that are covering the glottis plan and make the intubation of the airway difficult or impossible.

The design of the instrument is a conical tube, larger in the proximal part and smaller in the distal part. The tube has a reverse Ushaped section. A $140 \mathrm{~mm}$ handle is placed in the proximal part of the tube in order to push the tube into the patient's mouth, and by applying traction to the tube the anesthesiologist is able to suspend the larynx in order to expose the vocal cord and to slide the intubation tube into the tracheal area (fig. 3).

The reversed $U$ shaped section of the tube will give the anesthesiologist the opportunity to push the tumor away from the medial to the lateral part of the pharynx so the laryngeal area can be exposed (fig. 4).

We designed the intubation device in four sizes according to the size of the patient neck.

The large size tube has a length of $18 \mathrm{~cm}$ with the 25 $\mathrm{mm}$ proximal diameter and $18 \mathrm{~mm}$ for the distal diameter of the tube. The small size tube has a length of $19 \mathrm{~cm}$ with the $23 \mathrm{~mm}$ proximal diameter and $15 \mathrm{~mm}$ for the distal diameter of the tube. The extra small size tube has a length of $20 \mathrm{~cm}$ with the $24 \mathrm{~mm}$ proximal diameter and $13 \mathrm{~mm}$ for the distal diameter of the tube.

We propose to construct the intubation device from poly methyl acrylate (PMMA), a well-known common material (fig. 5). It has a light transmission of $92 \%$, so it is colorless and almost transparent. The transparent properties of this material allow the anesthesiologist to see through the device the surrounding anatomy.<smiles>CCC(C)(CC(C)(C)C)C(=O)OC</smiles>

Fig. 5. Formula of poly methyl methacrylate

The material is resistant to abrasion. The surface is hard and that allows us to push away the tumor from the glottis plan. From the point of view of the sterilization process, the PMMA intubation device can be sterilize both by EtO gas and Gamma radiation.
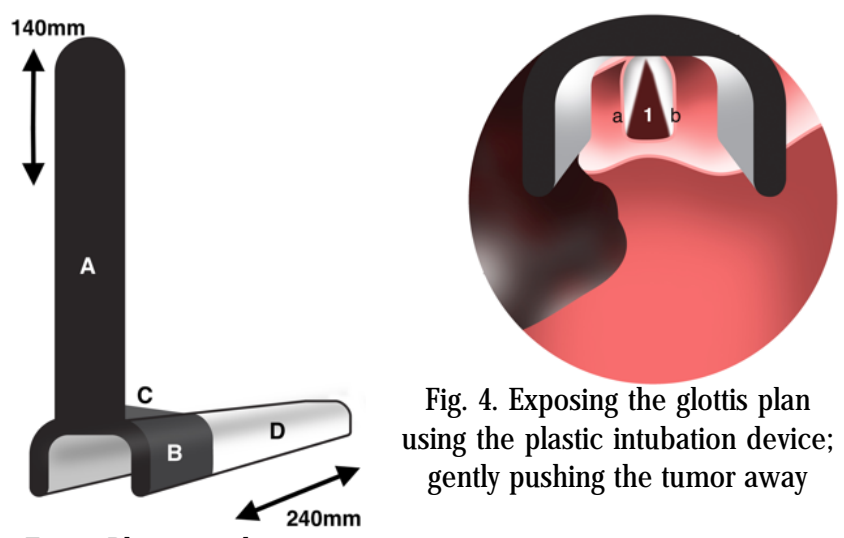

Fig. 4. Exposing the glottis plan using the plastic intubation device; gently pushing the tumor away

Fig. 3. Plastic intubation device design

EtO gas sterilization can be used without affecting the properties of the intubation device.

Using Gamma radiation and sterilization method will usually yellow the intubation device, but this is temporary.

The PMMA intubation device will maintain all its properties, such as strength, flexural properties, elasticity and elongation ratio.

PMMA is a lightweight material. It is very strong. The density varies between 1.17-1.2 $\mathrm{g} / \mathrm{cm}$, that is half of the density of glass. A good impactstrength is reported. It ignites at a temperature of $460^{\circ} \mathrm{C}$ and it will form carbon dioxide, water and carbon monoxide. PMMA is in a high degree compatible with human tissue. Intraocular lenses are manufactured from PMMS.

\section{Results and discussions}

We consider that PMMA intubation device will be a valuable tool to instrument the airway in difficultsituations. The good strength properties and resistance to abrasion recommends PMMA to be used as a construction material for the intubation device. It is highly compatible with the human tissue and no allergies were reported to PMMA. The lightweight of the device will make it easy to use, mainly in difficult situations. The $92 \%$ transmission of the light and colorless properties will allow the anesthesiologist to inspect the hypo pharyngeal area and to manipulate gently the tumor in order to prevent bleeding.

Further developments of the device can be made in order to attach a camera as well in order to better see the glottis plan on an LCD monitor.

\section{Conclusions}

In conclusion we consider that the PMMA intubation tube with the reversed $U$ shaped section allows the anesthesiologist to gently push away the tumors arising from the hypopharyngeal area. The transparent properties of the PMMA used as constructive material will allow the surgeon to inspect the hypopharyngeal and laryngeal area. Using PMMA to mold the intubation device is a good choice because of the high biocompatibility with the human tissue, with no reported allergies. The material has good strength, allowing the anesthesiologist to apply important forces to suspend the larynx, to visualize the glottis and to intubate the patient. Further developments of the intubation device can be made in order to attach a camera to the tip of the tube in order to visualize the glottis plan and to be able to record images and movies with the intubation. Recording evidences is extremely important, even from the medicolegal point of view. 
Acknowledgement: All authors have contributed equally to this manuscript.

\section{References}

1. DE JONG A, MOLINARI N, POUZERATTE Y, VERZILLI D, CHANQUES G, JUNG B, FUTIER E, PERRIGAULT PF, COLSON P, CAPDEVILA $X$, JABER S. Br j anaesth. 114, nr. 2, 2015, p. 297-306

2. NORSKOV AK, ROSENSTOCK CV, WETTERSLEV J, ASTRUP G, AFSHARI A, LUNDSTRØM LH. Anaesthesia. 70, nr. 3, 2015, p.272-81 3. FRECK CM, MITCHELL VS, MCNARRY AF. Br J Anesth ,115, 2015, p.827-48
4. AHMAD I, MILLHOFF B, J OHN M, ANDI K, OAKLEY R. J Clin Anesth. 27, nr. 6, 2015, p.508-13

5. STANCIU AE, ANTON A, ZAMFIR C, STANCIU MM. Romanian biotechnological letters, 22, nr. 2, 2017, p. 12419-26

6. BERTESTEANU SVG, POPESCU CR, GRIGORE R et. al. Chirurgia, 107, nr. 1, 2012, p. 33-38

7. POPESCU B, POPESCU CR, GRIGORE R et. al. Romanian J ournal of Morphology and Embriology, 53, nr. 2, 2012, p. 243-248.

8. YIPEL M., GHICA M., ALBU M.G. et al. Current Organic Chemistry, 20, nr. 28, 2016, p. 2934-2948

$\overline{\text { Manuscript received: } 18.06 .2017}$ 